\title{
Effect of Annealing Process on the Mechanical Properties of X70 Pipeline Steel
}

\author{
Teng-wei Zhu ${ }^{1}$, Cheng-liang Miao ${ }^{1}$, Zheng Cheng ${ }^{2}$, Zhipeng Wang ${ }^{1}$, Yang Cui ${ }^{1}$ and Fei $\mathrm{Li}^{1}$ \\ ${ }^{1}$ Shougang research institute of technology, Beijing 100043, China; \\ 2Shougang Jingtang Steel Company, Hebei Caofeidian 063210, China
}

\begin{abstract}
The influence of the mechanical properties of X70 pipeline steel under different annealing temperature was studied. The corresponding microstructure was investigated by the Field Emission Scanning Electron Microscopy. The results showed that the yield strength and the tensile strength both experienced from rise to decline with the increase of annealing temperature. The grain sizes were coarse and a large amount of cementite precipitated due to preserving temperature above $550{ }^{\circ} \mathrm{C}$, which induced matrix fragmentation and deteriorate the $-10{ }^{\circ} \mathrm{C}$ DWTT Toughness. There were little changes on the microstructure and mechanical properties when the annealing temperature was under $500^{\circ} \mathrm{C}$.
\end{abstract}

\section{Introduction}

With the increasing gas pressure and more harsh service conditions, long-distance pipeline is gradually required to possess thick wall, large caliber, high strength and toughness $[1,2]$. Generally, X70 and X80 are applied during most of the major projects all over the world with a thickness from $15 \mathrm{~mm}$ to $22 \mathrm{~mm}$. They are efficient, economic and can last for several decades and have been recognized as the mostly utilized steels for pipeline construction in the petroleum industry [3]. It is reported that $[4,5]$, heat treatment is usually adopted to achieve better comprehensive performance during the pipe making majorly for high-grade. Annealing is influential on the mechanical properties especially for low temperature toughness [6]. Cleavage fracture splits in separations are usually detected on such material after tensile test, impact test and DWTT (Drop Weight Tear Test) [7]. Cleavage in separations is a typical kind of fracture for controlled rolled steels, the mechanism of which however lacks of research. In the present work, the effect of annealing process on the mechanical properties was studied and the formation mechanism of cleavage in separations after DWTT was investigated.

\section{Experimental procedures}

\subsection{Materials and sample preparation}

The material studied in this work is X70 pipeline steel with thickness $20 \mathrm{~mm}$. The composition is shown in Table 1.

Table 1. Chemical composition.

\begin{tabular}{ccccc}
\hline $\mathrm{C} / \%$ & $\mathrm{Si} / \%$ & $\mathrm{Mn} / \%$ & $\mathrm{Nb}+\mathrm{V}+\mathrm{Ti} / \%$ & $\mathrm{Cr}+\mathrm{Cu}+\mathrm{Ni}+\mathrm{Mo} / \%$ \\
\hline 0.06 & 0.2 & 1.70 & $\leqslant 1.50$ & $\leqslant 0.60$ \\
\hline
\end{tabular}

The steel sample was taken from $1 / 4$ position of the width and $45^{\circ}$ to the rolling direction by flame cutting and was cut into rough samples with dimensions $420 \mathrm{~mm}$ $\times 65 \mathrm{~mm} \times \mathrm{T}$ used for tensile test, $45 \mathrm{~mm} \times 18 \mathrm{~mm} \times \mathrm{T}$ for impact test and $300 \mathrm{~mm} \times 90 \mathrm{~mm} \times \mathrm{T}$ for DWTT before heat treatment. 


\subsection{Experiment}

Muffle furnace was applied for annealing treatment on prepared samples. The samples were heated in the furnace up to $400 \sim 650{ }^{\circ} \mathrm{C}$. Preserved for 4 hours respectively before furnace cooling down to $150{ }^{\circ} \mathrm{C}$ and then taken out for air cooling. The annealing process is shown in Table 2.

Table 2. Annealing process.

\begin{tabular}{ccc}
\hline \multirow{2}{*}{ Sample No. } & \multicolumn{2}{c}{ Annealing process } \\
\cline { 2 - 3 } & Heating temperature & Preservation time \\
\hline $1 \#$ & \multicolumn{2}{c}{ Blank sample (Without heat treatment) } \\
\hline $2 \#$ & $400{ }^{\circ} \mathrm{C}$ & 4 hours \\
\hline $3 \#$ & $500{ }^{\circ} \mathrm{C}$ & 4 hours \\
\hline $4 \#$ & $550{ }^{\circ} \mathrm{C}$ & 4 hours \\
\hline $5 \#$ & $600^{\circ} \mathrm{C}$ & 4 hours \\
\hline $6 \#$ & $650^{\circ} \mathrm{C}$ & 4 hours \\
\hline
\end{tabular}

After annealing, the rough samples were machined into standard tensile samples (Gauge Length $50 \mathrm{~mm}$ ), impact test samples $(10 \times 10 \times 55 \mathrm{~mm})$ and DWTT samples (Pressed Notch). Tensile test was conducted on Zwick100 tensile test machine. The impact test was performed on PSW750 full automatic impact test machine from Zwick at a speed of $20 \mathrm{~mm} / \mathrm{min}$. The linear velocity at the point of impact was around $5.5 \mathrm{~m} / \mathrm{s}$. DWTT was performed on the JL40000 testing machine from China.

Using Metallography and Field Emission Scanning Microscope to investigate the microstructure after the samples were polished and eroded by $4 \%$ nital.

\section{Results and discuss}

\subsection{Tensile test}

The tensile properties with different annealing process are shown in Fig. 1. Rt0.5 and Rm goes through three stages with the increase of annealing temperature: (1) When the temperature is below $500^{\circ} \mathrm{C}$, Rt 0.5 increases with the annealing temperature very slightly while $\mathrm{Rm}$ stays the same; (2) After preserved under $550{ }^{\circ} \mathrm{C}$ for 4 hours, both Rt 0.5 and Rm increase remarkably. Besides, the increase of Rt0.5 excesses $\mathrm{Rm}$ and as a result, the yield ratio increase rapidly; (3) When the temperature is beyond $550{ }^{\circ} \mathrm{C}$, both Rt 0.5 and $\mathrm{Rm}$ decrease while the yield ratio changes little.

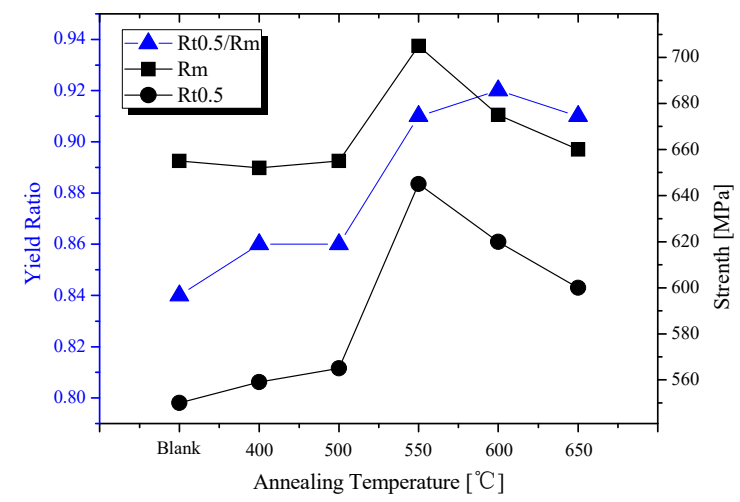

Fig. 1. Tensile test results of different annealing process.

The results of $-20{ }^{\circ} \mathrm{C}$ impact test and $-10{ }^{\circ} \mathrm{C}$ DWTT are shown in Fig. 2. The impact absorbed energy decreased with the increase of annealing temperature but the general level maintained in a fine condition. When the annealing up to $650{ }^{\circ} \mathrm{C}$, the absorbed energy can still be around $300 \mathrm{~J}$. The result of DWTT exhibited the same trend. When the annealing temperature was under $500{ }^{\circ} \mathrm{C}$, the shear ratio experienced little changes and stay around $100 \%$. However, the shear ratio of 4\#, 5\# and 6\# sample showed an obvious decrease. That is to say, the DWTT properties deteriorated when the annealing temperature was above $550^{\circ} \mathrm{C}$. The fracture morphologies are shown in Fig. 3. The fracture was mainly ductile when the annealing temperature is under $500{ }^{\circ} \mathrm{C}$ and became fragile with obvious separations when it was above $550{ }^{\circ} \mathrm{C}$

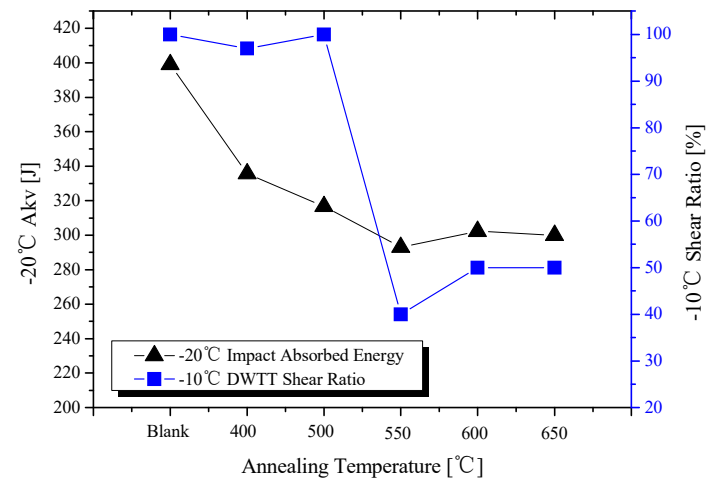

Fig. 2. Low temperature toughness with different annealing process. 


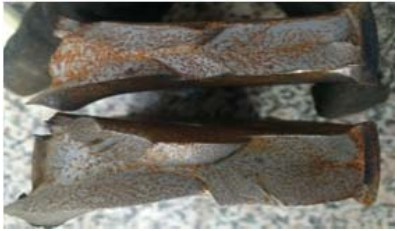

1\# Blank

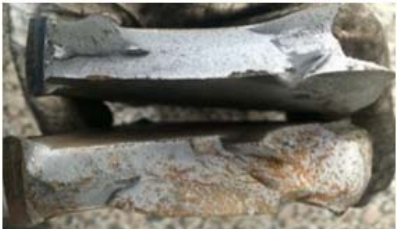

$3 \# 500{ }^{\circ} \mathrm{C}$

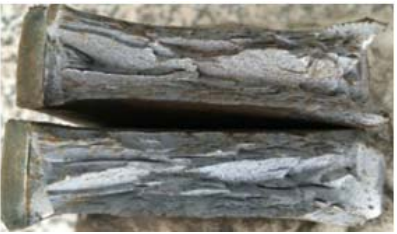

$5 \# 600{ }^{\circ} \mathrm{C}$

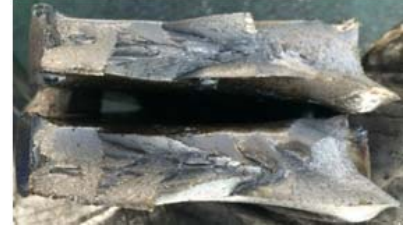

$2 \# 400{ }^{\circ} \mathrm{C}$

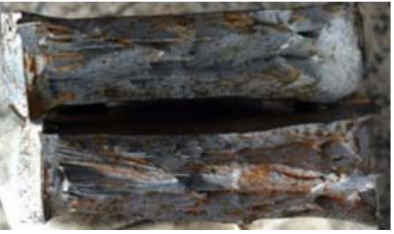

$4 \# 550{ }^{\circ} \mathrm{C}$

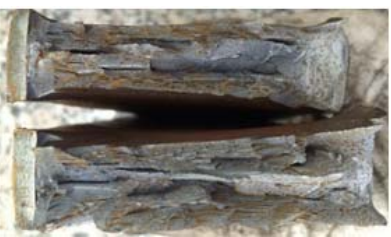

$6 \# 650{ }^{\circ} \mathrm{C}$
Fig. 3. DWTT fracture morphology.

\subsection{Microstructure observation}

The microstructure was observed by optical microscope and the result is shown in Fig. 4. The blank sample was dominated by acicular ferrite. There has been no significant change of microstructure when the annealing temperature was under $500{ }^{\circ} \mathrm{C}$. However, the grain size increased from $5 \mu \mathrm{m}$ to more than $10 \mu \mathrm{m}$ when it was above $550{ }^{\circ} \mathrm{C}$. The increase of grain size can become one of the main reasons of the decrease of low temperature impact properties.

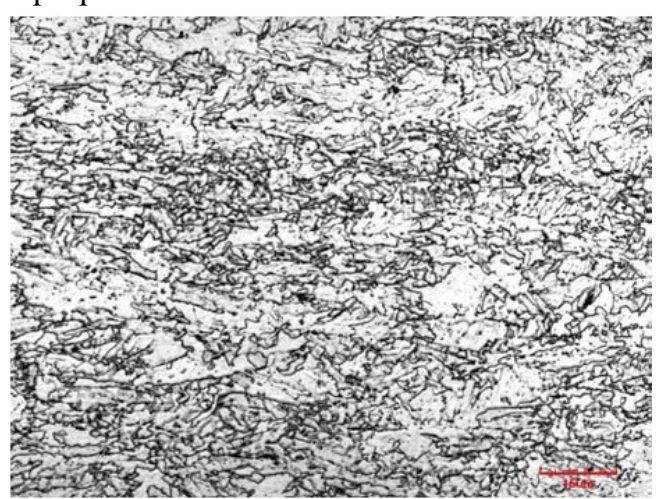

1\# Blank

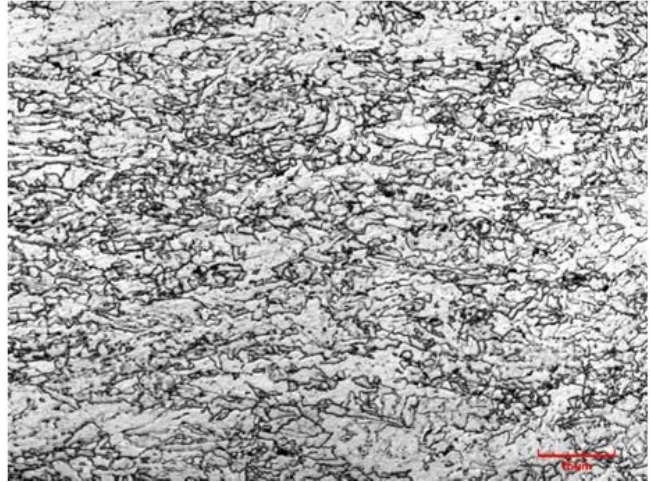

2\# $400{ }^{\circ} \mathrm{C}$

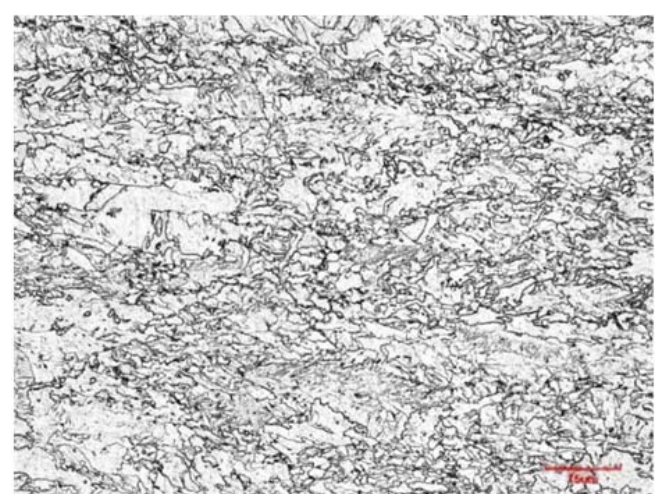

$3 \# 500{ }^{\circ} \mathrm{C}$

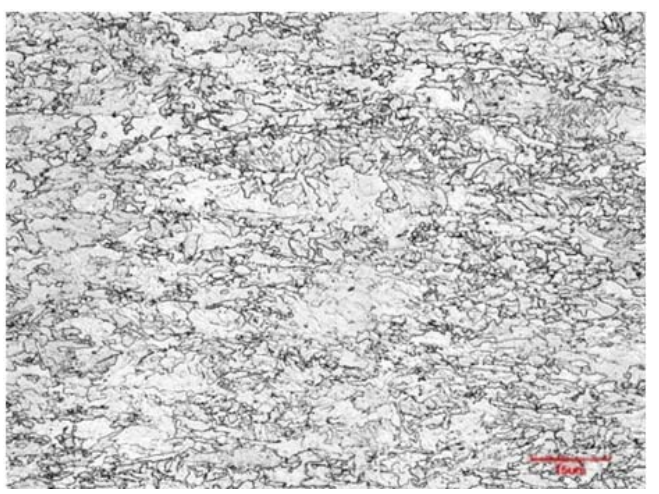

$4 \# 550{ }^{\circ} \mathrm{C}$

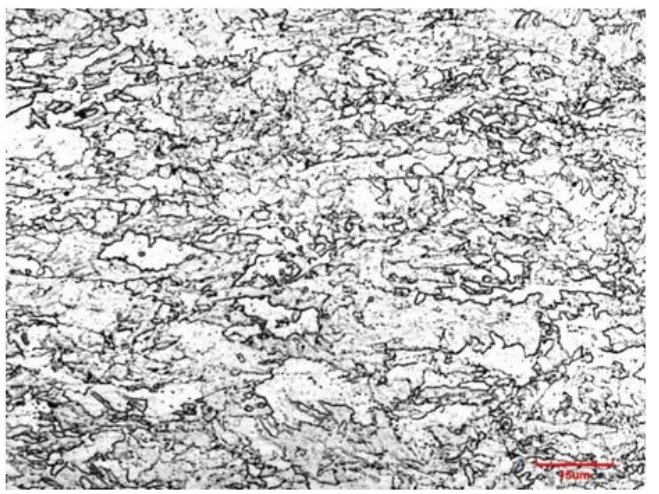

$5 \# 600{ }^{\circ} \mathrm{C}$ 


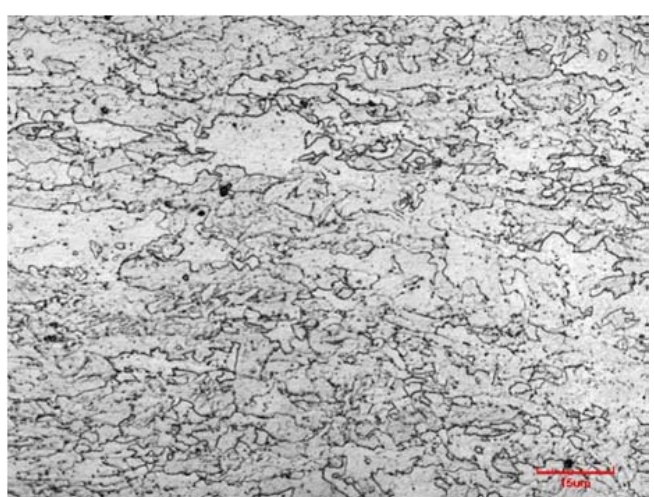

$6 \# 650{ }^{\circ} \mathrm{C}$

Fig. 4. Microstructure morphologies under different annealing process.

\subsection{Scanning Electron Microscopy Analysis}

The SEM microstructure morphologies are shown in Fig. 5. Mass precipitation particles were detected in $4 \#, 5 \#$ and $6 \#$ sample. The particles were mainly distributed in grain boundaries judged from $4 \#$ and $5 \#$ while even precipitated inside the grain of 6\#. That is to say, with the increase of annealing temperature, the precipitation particles increased both with their number and size. No obvious precipitation particles were observed when under $500^{\circ} \mathrm{C}$.

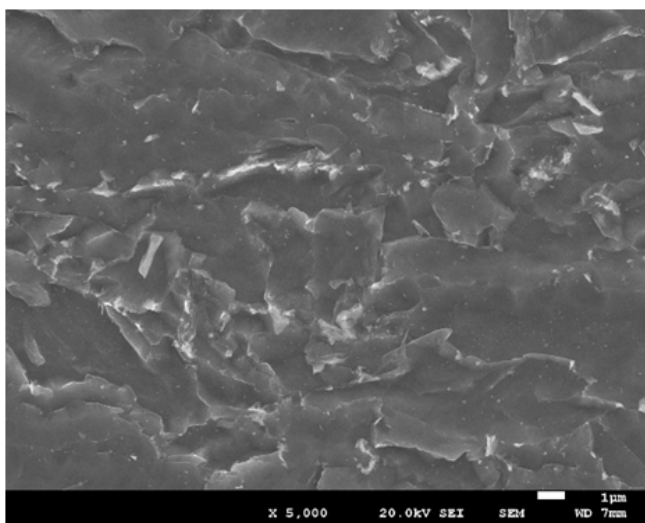

1\# Blank

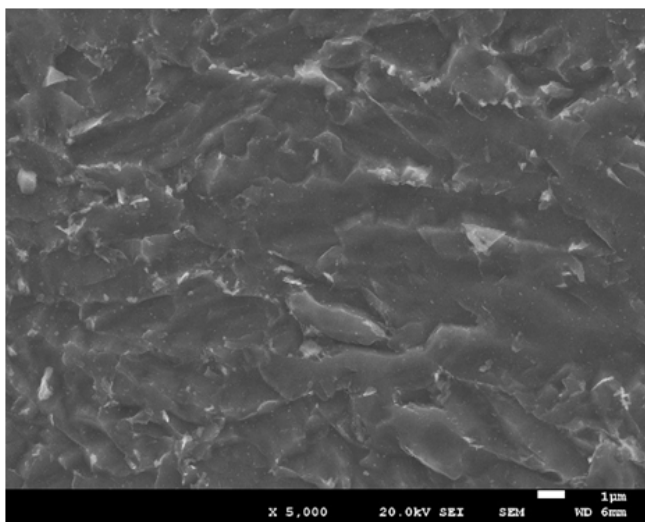

2\# $400{ }^{\circ} \mathrm{C}$

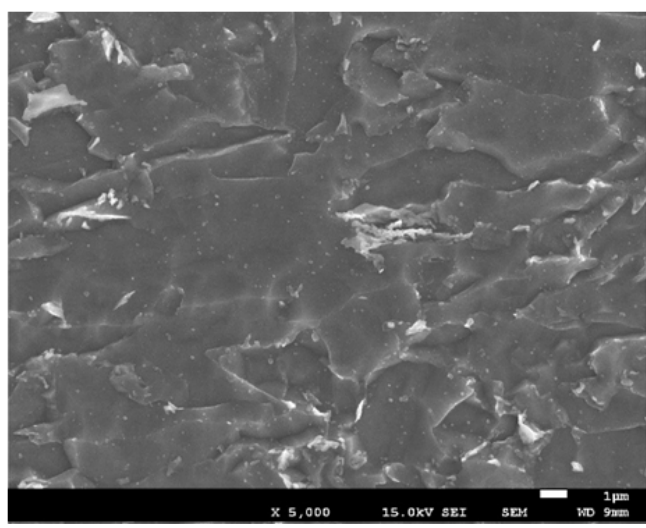

$3 \# 500{ }^{\circ} \mathrm{C}$

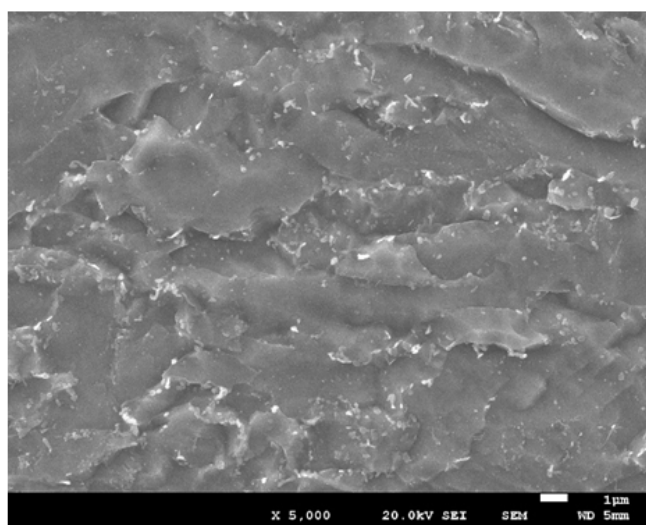

$4 \# 550{ }^{\circ} \mathrm{C}$

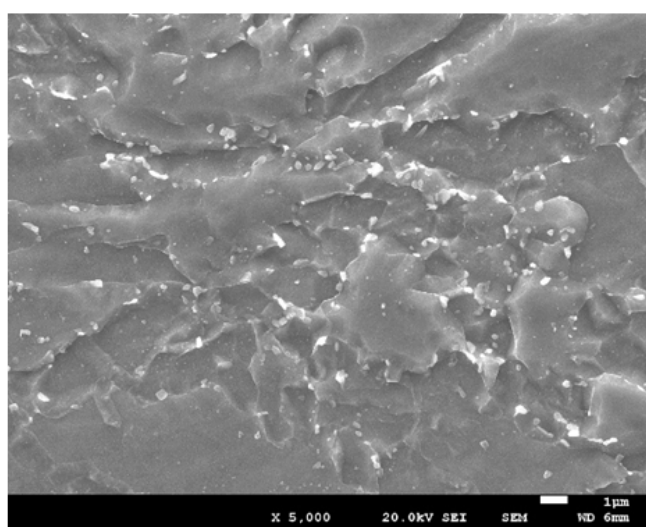

$5 \# 600{ }^{\circ} \mathrm{C}$

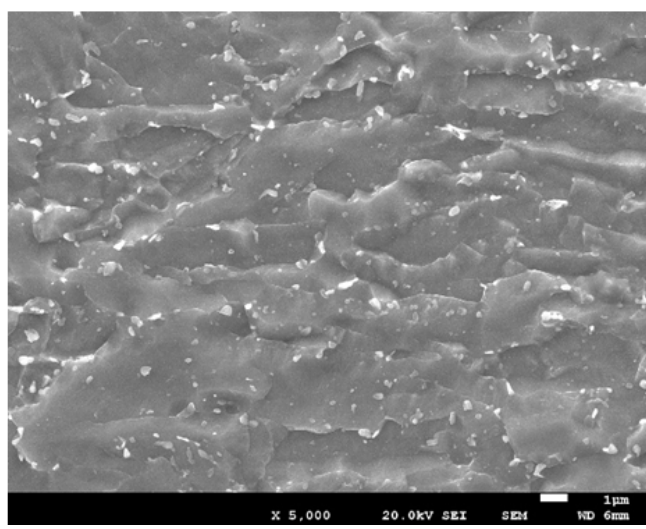

$6 \# 650{ }^{\circ} \mathrm{C}$

Fig. 5. SEM morphologies under different annealing process. 
In order to identify the precipitation particles, the energy spectrum analysis was conducted; the result is shown as Fig. 6 and Table 3. The particles are mainly cementite. The cementite precipitation particles can destroy the uniformity of the matrix $[8,9]$. When the material is faced to impact, the stress will concentrate on the junction of the precipitation particles and the matrix and finally lead to fracture.

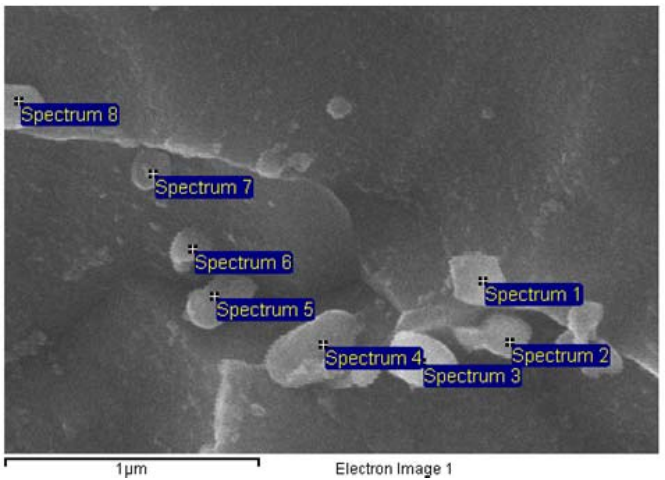

Fig. 6. Precipitation particles Energy Spectrum Analysis.

Table 3. Spectrum Results.

\begin{tabular}{c|cccccc}
\hline Spectrum & In & $\mathrm{C}$ & $\mathrm{Cr}$ & $\mathrm{Mn}$ & $\mathrm{Fe}$ & Total \\
stats. & & & & & \\
Spectrum 1 & Yes & 11.37 & 1.08 & 2.98 & 84.57 & 100.00 \\
Spectrum 2 & Yes & 14.59 & & 3.54 & 81.87 & 100.00 \\
Spectrum 3 & Yes & 13.84 & 1.65 & 5.91 & 78.60 & 100.00 \\
Spectrum 4 & Yes & 10.22 & & 4.41 & 85.37 & 100.00 \\
Spectrum 5 & Yes & 8.65 & & 3.06 & 88.29 & 100.00 \\
Spectrum 6 & Yes & 9.46 & & 2.12 & 88.42 & 100.00 \\
Spectrum 7 & Yes & 10.34 & & 2.41 & 87.25 & 100.00 \\
Spectrum 8 & Yes & 5.71 & & & 94.29 & 100.00 \\
\hline
\end{tabular}

All results in weight [\%]

The cleavage in separations morphology of DWTT fracture of $5 \#$ sample which preserved $4 \mathrm{~h}$ under $600^{\circ} \mathrm{C}$ is shown in Fig. 7. Massive initial cracks were detected on the direction which the crack travels. Inside these small initial cracks were the cementite precipitation particles. It is obvious that, the stress concentrated around the cementite precipitation particles and emerge initial cracks, more than several cracks began to grow and therefore caused the cleavage in separations and worsened the Low Temperature DWTT Toughness.
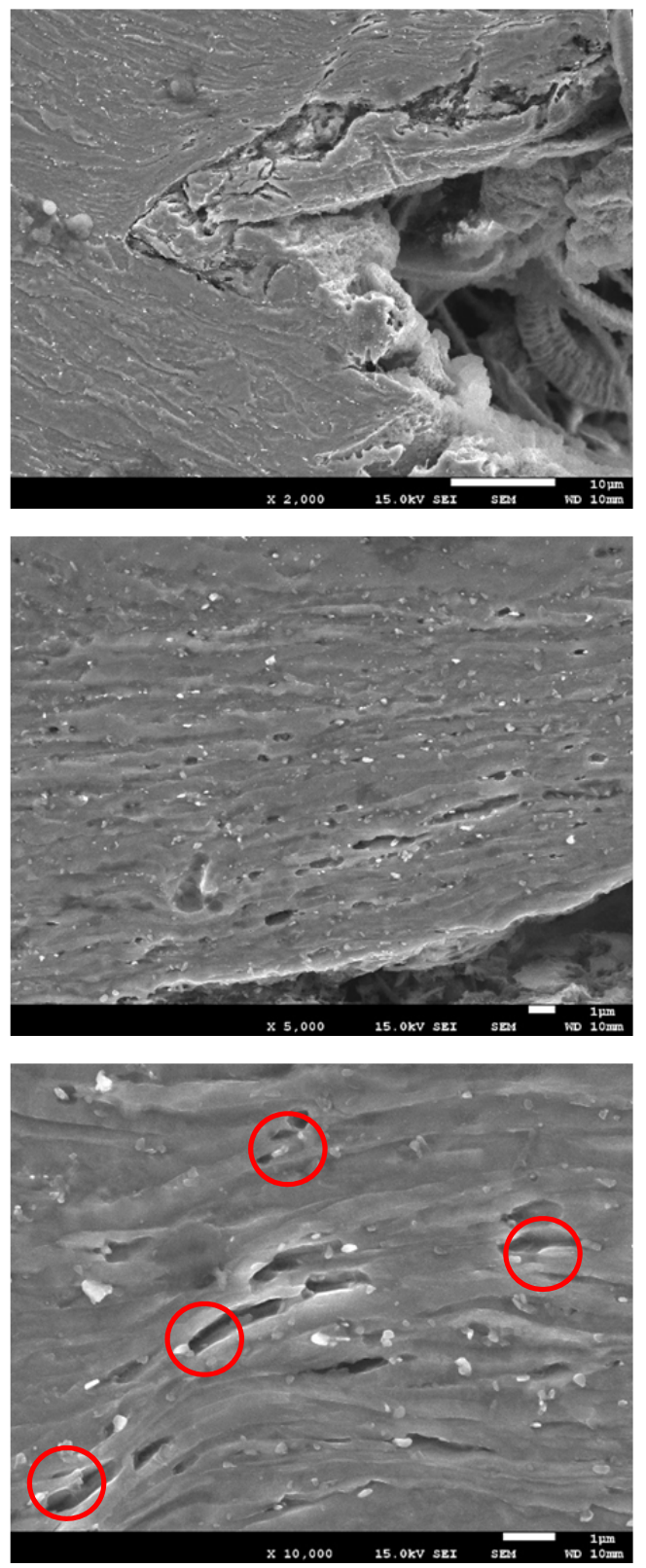

Fig. 7. Morphology of the cleavage in separations from DWTT fracture.

\section{Summary}

1) With the annealing temperature increases, the yield strength and the tensile strength of X70 pipeline steel both presented a trend from rise to decline. When the temperature reached $550{ }^{\circ} \mathrm{C}$, the yield ratio experienced a remarkable increase.

2) With the annealing temperature increases, the $-20{ }^{\circ} \mathrm{C}$ Impact Absorbed Energy decreases but the general level maintained in a fine condition. The $-10{ }^{\circ} \mathrm{C}$ DWTT performance worsen when it is above $550^{\circ} \mathrm{C}$. 
3) There is no significant change in microstructure when the annealing temperature is under $500{ }^{\circ} \mathrm{C}$. When it is above $550{ }^{\circ} \mathrm{C}$, massive cementite precipitation particles appear and the grain size grows up obviously which worsen the DWTT performance and caused the cleavage separations.

\section{Reference}

1. R Zheng. Shougang Science and Technology, 3, 7 11(2003)

2. K Tong, C Zhuang, L Zhu etc. Materials Review, 24, 98 101(2010)

3. N Narimani, B Zarei, H Pouraliakbar etc. Measurement, 62, 97 107(2015)
4. L Li, M Zheng, L Sun etc. Welded Pipe and Tube, 33,18 21(2010)

5. S Zhang, Y Ren, S Wang etc. Effect of Temper Process for the Structure and Property of High Strength Pipeline Steel. (Beijing: Metallurgical Industry Press, 2009)

6. W Zhao, L Zhao, Y Zhao etc. Materials for Mechanical Engineering, 39, 28 31(2015)

7. $\mathrm{Y} \mathrm{Li}, \mathrm{G}$ Lin, $\mathrm{L}$ Ji etc. Materials for Mechanical Engineering, 34, 14 18(2010)

8. $\mathrm{G} \mathrm{Li}, \mathrm{H} \mathrm{Xu}, \mathrm{H}$ Peng. Wide and Heavy Plate, 12, 5 8(2006)

9. R Zhang, Y Liu. Anhui Metallurgy, 2 ,21 28(2009) 